\title{
PREFACE
}

\section{THE $12{ }^{\text {TH }}$ INTERNATIONAL CONFERENCE ON HEALTH EFFECTS OF INCORPORATED RADIONUCLIDES}

\section{HEIR 2018}

The $12^{\text {th }}$ international conference on the health effects of incorporated radionuclides (HEIR 2018), took place in Fontenay-aux-Roses, from October 8 to October 11, 2018. Jointly organized by the French Institute of Radioprotection and Nuclear Safety (IRSN) and the Commissariat à l'Energie Atomique et aux Energies Alternatives (CEA), this international conference was the first one organized in France. The series began in 1974 in Alta (Utah, USA). Further ones followed almost every 3-4 years: Neuherberg (Germany) in 1976, Lisbon (Portugal) in 1977, Lake Geneva (Wisconsin, USA) in 1981, Neuherberg in 1984, Bethesda (Maryland, USA) in 1988, Heidelberg (Germany) in 1994, Tokyo (Japan) in 1999, Neuherberg in 2004, Santa Fe (New Mexico) in 2009 and Berkeley (California, USA) in 2013.

In the 1970s, the first HEIR conference has focused on radium and thorotrast health consequences; since then the spectrum of the conferences has extended to other radionuclides, such as radon and risk of cancer among uranium miners, mixed oxides of uranium and plutonium and their biological effects, more recently radioactive iodine and potential health effects after the Fukushima accident. The wide scope of technical, biological tools (for example 'omics technologies') and specific models developed contribute largely to address health and biological questions due to the human contamination by radionuclides.

The program was divided into 7 sessions: biokinetics, dose assessment, epidemiology, biological effects, medical countermeasures, nuclear medicine and what's next. For the first time in this series of conferences, a session was dedicated to the medical use of radioisotopes.

More than 140 scientists coming from Algeria, Belgium, Canada, Czech Republic, France, Germany, Hungary, Japan, Kazakhstan, Romania, Russia, Spain, Switzerland, United Arab Emirates, UK and USA, attended the conference. Over almost four days, more than 80 presentations or posters were given and discussed. All these contributions are collected in this new issue of Bio Web of conferences.

We would like to thank the members of the scientific committee for the evaluation process of the abstracts and the building of the scientific program. They are:

Rebecca Abergel, US

Makoto Akashi, Japan

Manuel Bardies, France

Luiz Bertelli, US

Jean-Marc Bertho, France

Eric Blanchardon, France

Xavier Castagnet, France

Augusto Giussani, Germany

Laurence Lebaron-Jacobs, France

Jin Kyung Lee, Korea

\author{
Valérie Lemercier, France \\ Balazs Madas, Hungary \\ Florence Menetrier, France \\ Brian Moyer, US \\ François Paquet, France \\ Tony Riddell, UK \\ Thierry Sarrazin, France \\ Patsy Thompson, Canada \\ Anne Van Der Meeren, France \\ Richard Wakeford, UK.
}

Moreover, we warmly thank the members of the organizing committee: Céline Dinocourt, Sarah Le Hir, Caroline Salhab, Fabrice Ecrabet, Keltoum Mediana for providing a very nice welcome, organizing secretary, partnership, communication and media.

Professional Societies SFRP, SoFRa, SFMN and SFPM are thanked for their scientific or technical support, so as Cevidra Society for its grant. We would like to thank specifically the Board of the Multidisciplinary European LowDose Initiative MELODI for its financial support having allowed the Young Investigator Award.

Finally, we hope that you will read with pleasure these proceedings of HEIR 2018.

Jean-Marc Bertho and Florence Menetrier

Co-chair of the HEIR2018 conference 